\title{
Tumor de Células de Leydig num Doente com \\ Criptorquidia Contralateral: Uma Associação Rara
}

\author{
Leydig Cell Tumor in a Patient with Contralateral \\ Cryptorchidism: A Rare Association
}

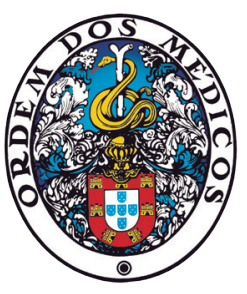

\author{
Ricardo CAPITÃO $\rrbracket^{1}$, Catarina SARAIVA¹, Clara CUNHA ${ }^{1}$, Mónica MARTINS ${ }^{2}$
}

Acta Med Port 2021 Feb;34(2):137-139 - https://doi.org/10.20344/amp.11882

\begin{abstract}
RESUMO
A ginecomastia é um sinal frequente que pode ser fisiológica ou causada por várias doenças benignas ou malignas. Em casos raros pode ser originada por tumores testiculares. Nós descrevemos um caso de ginecomastia de início rapidamente progressivo aos 20 anos por um tumor de células de Leydig do testículo direito em doente com história pregressa de criptorquidia esquerda. O doente foi submetido a orquidectomia e colocação de prótese testicular assistindo-se a melhoria da ginecomastia e normalização dos valores de estrogénio. O nosso caso, além de demonstrar que a ginecomastia pode regredir se a causa subjacente for tratada atempadamente, mostra que a criptorquidia poderá estar associada ao aparecimento de tumores de células de Leydig à semelhança do que acontece com outros tumores testiculares.
\end{abstract}

Palavras-chave: Criptorquidismo; Ginecomastia; Neoplasias Testiculares; Tumor de Células de Leydig

\section{ABSTRACT}

Gynecomastia is a frequent sign that may be physiological or caused by various benign or malignant diseases. In rare cases, it may be caused by testicular tumors. We describe a case of progressive gynecomastia at age of 20 due to a Leydig cell tumor of the right testicle in a patient with a previous history of left-sided cryptorchidism. The patient underwent orchidectomy and testicular prosthesis placement, with subsequent improvement of gynecomastia and normalization of estrogen. Our case, in addition to demonstrating that gynecomastia may regress if the underlying cause is treated in a timely manner, shows that cryptorchidism may be related with the development of Leydig cell tumors in the same way as it is in other testicular tumors.

Keywords: Cryptorchidism; Gynecomastia; Leydig Cell Tumor; Testicular Neoplasms

\section{INTRODUÇÃO}

A ginecomastia é definida como a proliferação do epitélio ductal da glândula mamária e pode ser causada por várias doenças benignas ou malignas. ${ }^{1}$ Resulta de uma alteração da relação entre estrogénio e androgénios ao nível do tecido mamário com predomínio da ação estrogénica sobre o mesmo, pelo que, qualquer causa que conduz à diminuição da ação dos androgénios ou aumento da ação estrogénica é passível de poder cursar com ginecomastia. ${ }^{2}$

Os tumores primários do testículo são uma causa rara de ginecomastia, apresentando uma incidência de 3 - 10/ 100000 homens por ano nas sociedades ocidentais, dos quais apenas $3 \%$ são tumores de células de Leydig (TCL). Até à data foram publicados cerca de 250 casos de tumores de células de Leydig. ${ }^{3}$

Os TCL pertencem ao subgrupo dos tumores estromais sexuais testiculares e, devido à sua baixa prevalência, a sua etiologia não é totalmente compreendida. Ao contrário de outros tumores testiculares, a criptorquidia não constitui um fator de risco para o desenvolvimento de TCL. ${ }^{4}$

Os TCL podem ser hormonalmente não-secretores ou secretar uma variedade de hormonas, incluindo testosterona e estrogénio. No entanto, a presença de sintomatologia ocorre em apenas $20 \%$ a $40 \%$ dos casos. ${ }^{4}$

Os doentes podem apresentar uma massa testicular palpável e, no caso das crianças, podem desenvolver puberdade precoce, ginecomastia assimétrica uni ou bilateral.
Nos adultos, além da ginecomastia, pode ocorrer disfunção sexual erétil, diminuição da libido ou infertilidade. ${ }^{3}$

\section{CASO CLÍNICO}

Doente do sexo masculino, 20 anos, recorreu à consulta por ginecomastia bilateral com quatro meses de evolução, indolor, sem outros sintomas associados.

Como antecedentes pessoais apresentava história de orquidopexia esquerda e herniorrafia inguinal direita na infância, por criptorquidia esquerda e hérnia inguinal direita, respetivamente.

Referia início da puberdade no mesmo tempo que os pares e negava ingesta de suplementos alimentares, fármacos ou alterações do padrão alimentar.

Apresentava antecedentes familiares de dois casos de cancro da mama em duas tias maternas aos 55 e 57 anos, sem outros antecedentes relevantes.

Ao exame objetivo salientava-se: peso $69 \mathrm{~kg}$, altura $1,73 \mathrm{~cm}$, índice de massa corporal (IMC) $23,07 \mathrm{~kg} / \mathrm{m}^{2}$, pressão arterial (PA) $120 / 51 \mathrm{mmHg}$, frequência cardíaca (FC) 58 bpm, biótipo longilíneo sem distribuição ginóide da gordura corporal, aparência virilizada (voz masculina, barba e distribuição pilosa adequada), ambos os testículos nas bolsas escrotais com cerca de $25 \mathrm{~mL}$ (estádio 5 de Tanner) com consistência mantida e sem massas palpáveis e ginecomastia bilateral (Fig. 1).

\footnotetext{
1. Serviço de Endocrinologia. Hospital Egas Moniz. Lisboa. Portugal.

2. Unidade de Saúde Familiar do Dafundo. Lisboa. Portugal.

$\square$ Autor correspondente: Ricardo Capitão. ricardomiguelcapitao@gmail.com

Recebido: 01 de fevereiro de 2019 - Aceite: 12 de julho de 2019 - First published: 22 de setembro de 2020 - Online issue published: 01 de fevereiro de 2021 Copyright $\odot$ Ordem dos Médicos 2021
} 


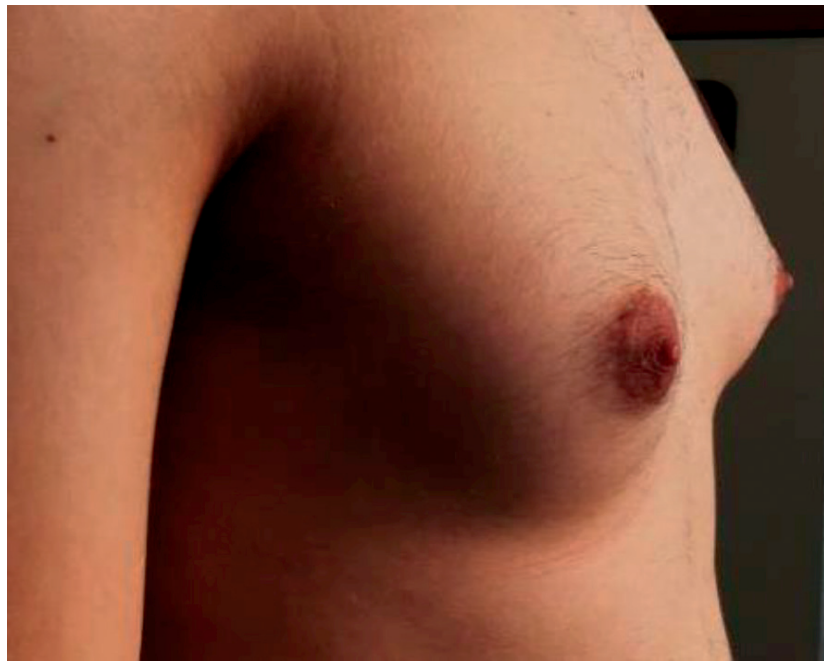

Figura 1 - Ginecomastia à data da observação (quatro meses após início da ginecomastia)

Analiticamente destacavam-se os seguintes parâmetros e respetivos valores normais de referência do laboratório [entre parênteses]: $\mathrm{FSH}<1,0 \mathrm{U} / \mathrm{L}[1,5-12,4 \mathrm{U} / \mathrm{L}], \mathrm{LH}$ $5,96 \mathrm{U} / \mathrm{L}[1,7-8,6 \mathrm{U} / \mathrm{L})]$, testosterona total $88 \mathrm{ng} / \mathrm{dL}$ [249 - 836], HCG < 0,6 U/L, alfa-fetoproteína < $10 \mathrm{ng} / \mathrm{mL}$, estradiol $61,9 \mathrm{pg} / \mathrm{mL}[27,0-52,2 \mathrm{pg} / \mathrm{mL}]$, DHEA-SO $4275 \mu \mathrm{g} /$ $\mathrm{dL}[211-492 \mu \mathrm{g} / \mathrm{dL}]$, progesterona $0,45 \mathrm{ng} / \mathrm{mL}[<0,15 \mathrm{ng} /$ $\mathrm{dL}$ ], delta-4-androstenediona $2,1 \mathrm{ng} / \mathrm{mL}[0,6-3,1 \mathrm{ng} / \mathrm{mL}]$, 17-OH-progesterona $2,2 \mathrm{ng} / \mathrm{mL}[0,60-3,44 \mathrm{ng} / \mathrm{mL}]$, prolactina $10,1 \mu \mathrm{g} / \mathrm{L},[4,0$ - 15,2] e TSH 2,9 $\mu \mathrm{Ul} / \mathrm{mL}[0,27$ - 4,20].

A ecografia mamária confirmou a presença de ginecomastia dendrítica bilateral moderada (BI-RADS: 2 bilateralmente). Foi solicitada ecografia escrotal que revelou um nódulo sólido parenquimatoso com $16 \mathrm{~mm}$ no interior do testículo direito, hipoecogénico, com aumento da vascularização no estudo Doppler.

O doente foi referenciado à consulta de Urologia e, após exclusão de lesões secundárias por tomografia computorizada (TC) toraco-abdomino-pélvica, foi realizada orquidectomia direita com colocação de prótese testicular. O resultado histológico foi compatível com tumor de células de Leydig de $14 \times 13 \mathrm{~mm}$, totalmente excisado.

$O$ doente foi reavaliado quatro meses após cirurgia, tendo-se documentado regressão da ginecomastia, aumento da pilosidade axilar e torácica (Fig. 2) e melhoria dos parâmetros laboratoriais: FSH 11,6 U/L, LH 13,1 U/L, estradiol $38,7 \mathrm{pg} / \mathrm{mL}$, testosterona total $699 \mathrm{ng} / \mathrm{dL}$.

\section{DISCUSSÃO}

O presente caso ilustra uma etiologia rara de ginecomastia. Neste caso, o aparecimento de ginecomastia após o desenvolvimento pubertário completo e o seu início súbito fez suspeitar de uma causa patológica de ginecomastia. ${ }^{2}$

A elevação dos estrogénios com LH normal e testosterona diminuída sugeriram o diagnóstico de uma massa testicular que posteriormente se confirmou por ecografia escrotal.

A criptorquidia está associada a um risco aumentado de neoplasias testiculares com risco de transformação ma-

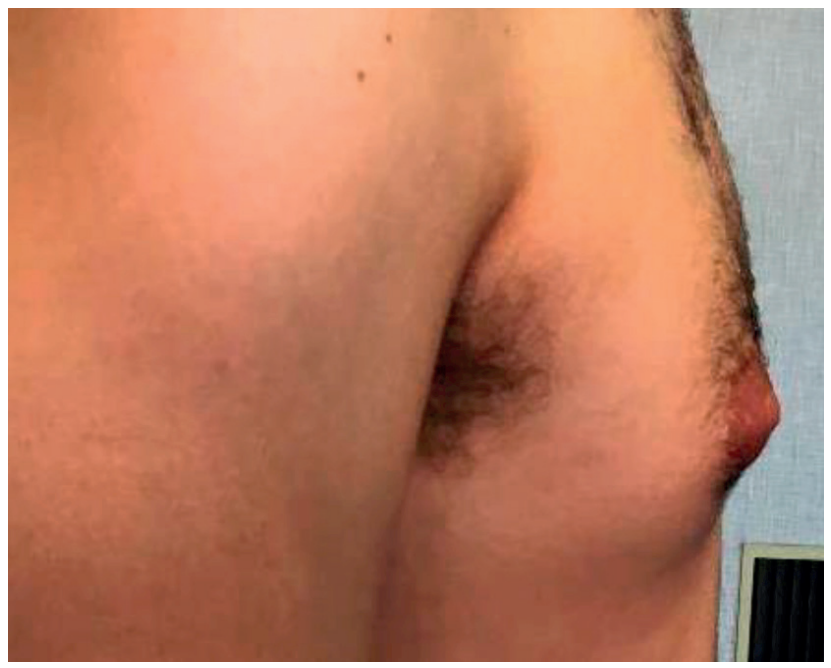

Figura 2 - Resolução da ginecomastia quatro meses após orquidectomia

ligna 20 - 30 vezes superior face à população em geral. Em cerca de $20 \%$ dos casos relatados, os tumores desenvolvem-se no testículo contralateral como sucedeu neste caso. ${ }^{5,6}$

Existindo a possibilidade de se tratar de um tumor de células germinativas, no qual pode ocorrer disseminação tumoral associada à biópsia da massa, optou-se por orquidectomia unilateral direita ao invés da biópsia testicular. ${ }^{7}$

Contudo, é interessante verificar que a associação com criptorquidia está descrita para tumores de células germinativas e não para TCL. Todavia, existe pelo menos um outro relato de caso semelhante. ${ }^{8}$

No nosso caso a elevação dos valores de estrogénios está relacionada com o aumento da atividade intrínseca da aromatase nas células tumorais dos TCL. Os estrogénios inibem, subsequentemente, o eixo hipotálamo-hipófise e a atividade da 17 - 20 liase responsáveis, respetivamente, pela diminuição da FSH e aumento da progesterona verificados. $^{9}$

Apesar dos TCL apresentarem um comportamento benigno na maioria dos casos descritos, é fulcral o diagnóstico atempado, uma vez que a ginecomastia pode reverter se a causa subjacente for tratada na fase inicial, como ilustra este caso. É importante salientar que, quando a ginecomastia persiste por mais de seis meses pode associar-se a fibrose, com diminuição das taxas de sucesso terapêutico. $^{10}$

\section{PROTECÇÃO DE PESSOAS E ANIMAIS}

Os autores declaram que os procedimentos seguidos estavam de acordo com os regulamentos estabelecidos pelos responsáveis da Comissão de Investigação Clínica e Ética e de acordo com a Declaração de Helsínquia da Associação Médica Mundial publicada em 2013.

\section{CONFIDENCIALIDADE DOS DADOS}

Os autores declaram ter seguido os protocolos do seu centro de trabalho acerca da publicação de dados. 


\section{CONSENTIMENTO DO DOENTE}

Obtido.

\section{CONFLITOS DE INTERESSE}

Os autores declaram a inexistência de conflitos de interesse na realização do presente trabalho.

\section{REFERÊNCIAS}

1. Costanzo PR, Pacenza NA, Aszpis SM, Suárez SM, Pragier UM, Usher JGS, et al. Clinical and Etiological Aspects of Gynecomastia in Adult Males: A Multicenter Study. Biomed Res Int. 2018. [consultado a 2019 out 01]. Disponível em: https://www.hindawi.com/journals/ bmri/2018/8364824/.

2. Carlson HE. Approach to the patient with gynecomastia. J Clin Endocrinol Metab. 2011;96:15-21.

3. Tazi MF, Mellas S, Fassi MJ, Farih MH. Leydig cell hyperplasia revealed by gynecomastia. Rev Urol. 2008;10:164-7

4. Leonhartsberger N, Ramoner R, Aigner F, Stoehr B, Pichler R, Zangerl $F$, et al. Increased incidence of Leydig cell tumours of the testis in the era of improved imaging techniques. BJU Int. 2011;108:1603-7.

5. Gill B, Kogan S. Cryptorchidism: current concepts. Pediatr Clin North

\section{FONTES DE FINANCIAMENTO}

Os autores declaram por sua honra que não foram utilizados quaisquer incentivos monetários ou outros para a realização do presente trabalho.

Am. 1997;44:1211-27.

6. Grasso M, Buonaguidi A, Lania C, Bergamaschi F, Castelli M, Rigatti P. Postpubertal cryptorchidism: review and evaluation of the fertility. Eur Urol. 1991;20:126-8.

7. Shaida N, Berman LH. Percutaneous testicular biopsy for indeterminate testicular lesions. Br J Radiol. 2012;85:S54-8.

8. Dounis A, Papacharalampous A. Clinically occult Leydig cell tumor in a cryptorchid man. Report of a case presenting with unilateral gynecomastia and impotence. Eur Urol. 1997;32:368-70.

9. Shimp WS, Schultz AL, Hastings JR, Anderson WR. Leydig-cell tumor of the testis with gynecomastia and elevated estrogen levels. Am J Clin Pathol. 1977;67:562-6.

10. Braunstein GD. Gynecomastia. N Engl J Med. 2007;357:1229-37. 